\title{
Distribution and Historical Trends of PAHs Deposition in Recent Sediment Cores of IMO River, S. E. Nigeria
}

\author{
Inyang O. Oyo-Ita ${ }^{\mathrm{a}}$, Orok E. Oyo-Ita ${ }^{\mathrm{a}^{*}}$, Miranda I. Dosunmu ${ }^{\mathrm{a}}$ and Soumaya Elarbaoui ${ }^{\mathrm{b}}$
}

\begin{abstract}
The distribution and historical changes of polycyclic aromatic hydrocarbons (PAHs) contamination in recent sediment cores from the Imo River were investigated using gas chrimatography-mass spectrometry (GC-MS). The concentrations of total PAHs (TPAHs-sum of parent and alkyl) ranging from 402.37 $\mathrm{ng} / \mathrm{g}$ dry weight (dw) at the surface layer of the Estuary zone (ESC6; $0-5 \mathrm{~cm}$ ) to $92,388.59 \mathrm{ng} / \mathrm{g} \mathrm{dw}$ at the near surface layer of the Afam zone (ASC5; 5-10 cm) indicate that PAHs contamination was localized not only between sample sites but also within the same cores. Sediment-depth profiles for the four (Afam, Mangrove, Estuary and illegal Petroleum refinery) cores revealed irregular distribution patterns in the TPAH concentrations except the fact that these levels became maximized at the near surface layers $(5-10 \mathrm{~cm})$ corresponding to a geological time-frame of about 1996-2004. This time scale coincided with the period of intensive bunkering and oil pipeline vandalization by the Niger Delta militant groups. Also a general slight decline was found in the TPAHs levels from near the surface layers $(5-10 \mathrm{~cm})$ to the most recent top layers $(0-5 \mathrm{~cm})$ of the cores, attributable to the recent effort by the Nigerian government in clamping down the illegal activity of the economic saboteurs. Therefore, the recent amnesty period granted the militant groups should be extended. Examination of perylene distributions down cores revealed natural biogenic (terrestrial), pyrogenic and petrogenic origins for the compound at different zones. Thus, the characteristic features of the Imo River environment provide a means of tracing diverse origins for perylene.
\end{abstract}

Keywords--Distribution, historical trend, Imo River and perylene.

\section{INTRODUCTION}

$\mathrm{P}$ OLYCYCLIC aromatic hydrocarbons (PAHs) have been listed as priority compounds due to their carcinogenicity, mutagenity, acute toxicity and persistency in the environment [2]. As time increases, the deposition of contaminants led to the differences in the distribution of PAHs at different depth intervals. In other words, diverse distributions of PAHs in different years are recorded in sediment due to differences in energy structure and economic development [8]. Therefore, it is very important to analyze sediment cores in order to understand the historical trends of PAHs deposition in the Imo river region. So far, the temporal historical trends of PAHs in sediment cores have been studied extensively around the world [eg. 8, 9], and many of them showed that the temporal trends corresponded to the vertical distributions in sediment cores.

${ }^{a}$ Environmental/Petroleum Geochemistry Research Group, Department of Pure \& Applied Chemistry, University of Calabar, Nigeria.

${ }^{b}$ Laboratory of Biomonitoring of the Environment, Coastal Ecology and Ecotoxicology Unit, University of Carthage, Faculty of Sciences of Bizerte, 7021, Zarzouna, Tunisia.
However, the knowledge of historical trends of PAHs sources in tropical African countries is relatively limited. To our knowledge, this is the first investigation on historical trends of PAHs contamination in the imo river sediments that reflects events that occurred since the first commercial discovery of crude oil in Nigeria in 1956.

Perylene, a 5-ring PAH has been extensively reported by many researchers in marine, lake, river and estuarine sediments to have diverse origins including non-marine oils [7]; natural gas combustion product [12]; insitu terrigenous and/or aquatic organic carbon production [4,] and tropical termite mounds [15]. Thus, the origin of perylene has been a matter of continued debate as the mechanism of its formation still remains enigmatic.

The Imo River environment represents one of the few environments suitable for the investigation of the diverse origins of perylene with the view of having an insight into the mechanism of its formation in the nearest future. This is because its environmental characteristics provide a means of tracing both natural (terrestrial and aquatic) and anthropogenic (petrogenic and pyrogenic) origins for the compound. Therefore, the main objectives of the present study were to: (i) delineate the distribution of PAHs in sediment cores of the study area, (ii) determine the historical trends of PAHs deposition over the last approximately 5 decades and (iii) investigate the diverse origins of perylene in a single sedimentary environment.

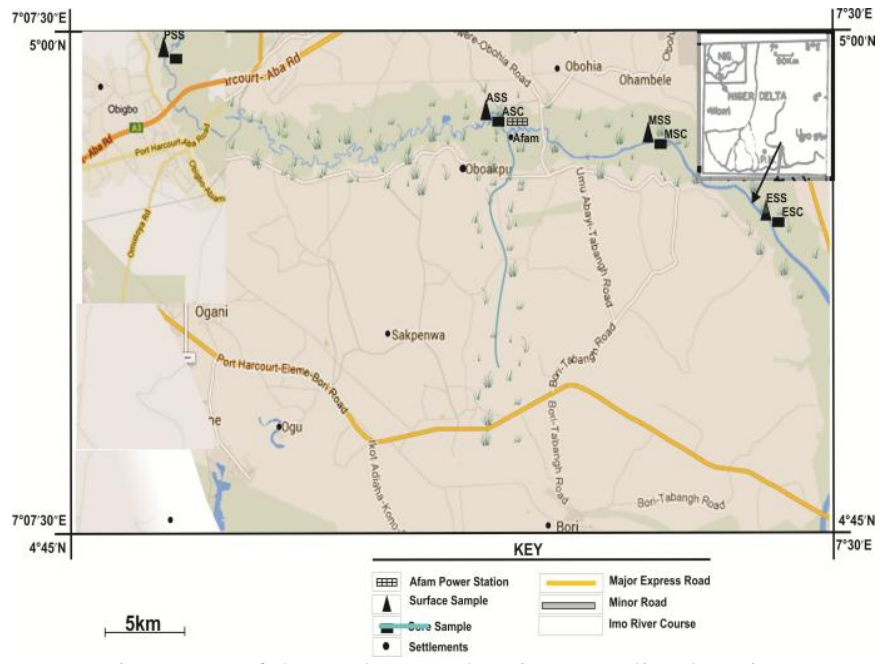

Fig.1 Map of the study area showing sampling location

\section{EXPERIMENTAL METHODS}

\section{A. Materials}

The following analytical grade solvents including n-hexane, acetone, isooctane and ethyl acetate were provided by Dr. Ehrenstofer GmbH (Augsburg, Germany). Silica gel (0.063-0.200 $\mathrm{mm}$ ), anhydrous sodium sulfate and aluminum oxide active neutral $(0.063-0.200 \mathrm{~mm})$ were obtained from Merck. 


\section{B. Samples and Radiometric Analysis}

Detail about the study area is as described in [13]. Fig. 1 shows location of the study area indicating sampling sites. The Imo River was divided into four different zones, each zone made up of one sediment core of $30 \mathrm{~cm}$ long(designed to correspond to a dated timescale of about 5 decades to coincide with the period of first commercial discovery of crude oil in Nigeria). Each core was cut into 6 sections of $5 \mathrm{~cm}$ interval.

Zone I consists of samples obtained near thick mangrove vegetation stands (MSC1-6) expected to contain dominant terrestrial organic carbon (OC); zone II consists of samples obtained near Afam Power Station site (ASC1-6) where natural gas combustion takes place; zone III consists of samples collected near illegal local petroleum refinery site (PSC1-6) and zone IV consists of samples collected near the estuary (ESC1-6) where commercial fishery activity takes place. All samples were obtained using a calibrated PVC corer, wrapped with pre-cleaned aluminum foil, kept in a cooler containing ice, brought to the laboratory and stored at $-20^{\circ} \mathrm{C}$ in a refrigerator until further processing.

Sediment cores from Mangrove, Afam and illegal Petroleum refinery zones were analyzed by radiometric method as described in [1]

\section{Grain Size, TOC and TN Determinations}

Sediment samples were crushed lightly to free individual particles and detail of grain size determination is as described in [13].

The determination of total organic carbon (TOC) and total nitrogen (TN) contents was performed by flash combustion at $1024^{\circ} \mathrm{C}$, followed by thermic conductivity detection in triplicate in a CHNS Elemental Analyzer, Carlo Erbar 1108.

\section{Extraction and Clean-up}

Prior to extraction protocol, sediment samples were "spiked" with the perdeuterated surrogates (naphthalene- $d_{8}$, anthracene- $d_{10}$, pyrene$d_{10}, \quad$ benzo[a]pyrene- $d_{12}, \quad$ benz[a] anthracene- $d_{12}$ and triphenylamine(TPhA) as internal standards. The extraction and clean up procedures are as described in [13].

\section{E. Instrumental Analysis and Quality Assurance/Control}

Analysis of the aromatic fractions was accomplished with a TRACE GC-MS Thero-Finnigan (Manchester, UK) in the electron impact (EI) mode at $70 \mathrm{eV}$. A 30-m, 0.25-mm-inner diameter capillary column coated with $0.25 \mu \mathrm{m}$ of ZB-5MS stationary phase (Phenomenex Zebron; USA) was used. Detail of column, transfer line and ion source temperature programs as well as quality assurance/control and qualitative/quantitative procedures are as described in [12].

Deuterated analogues were used for both recovery (60\% to $130 \%$, except naphthalene - $40 \%$ recovery) and quantification corrections. The relative standard deviations $(n=3)$ were calculated $(\mathrm{RSD}=<20$, except naphthalene -23\%)).

\section{RESULTS AND DISCUSSION}

A. Spatial and Vertical Distribution of PAHs in Estuary and Afam Sediment Cores.

Generally, the prevalence of spatial variation in PAHs concentrations in the four sediment cores might be ascribed to differences in hydrodynamic regimes related to the present and past river discharges and tidal influx, changes in sediment particle size characteristics in the individual cores and non-homogenous inputs from point-sources and non-point-sources of PAHs in the region under study.

The PAHs distribution by number of rings observed for the surface sediment of the Afam core was as follows: 2->3->4->5->6rings characteristic of dominant crude oil input, while a 2->5->4->3- >6-rings trend was found for the Estuary zone, indicative of a mixed source scenario with an enhanced pyrogenic inputs (Fig. 2a, b).

\section{Afam core rings}

(a)

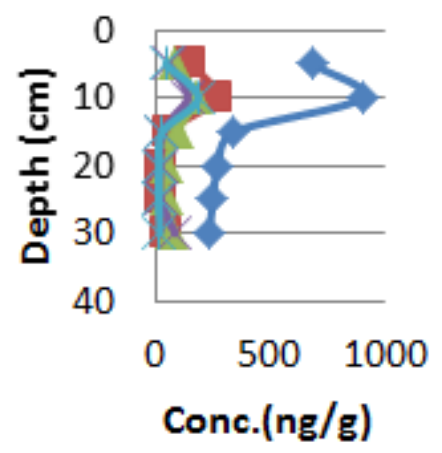

$\leadsto-\sum 2-$ RINGS

$-\sum 3-R I N G S$

$-\sum 4-R I N G S$

$\because \sum 5-R I N G S$

$-\Sigma$ - 6 -RINGS

\section{Estuary core rings}

(b)
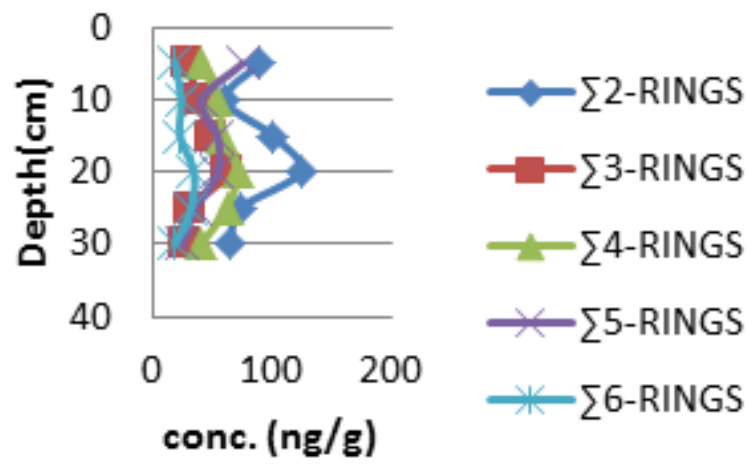

$\leftarrow \Sigma 5-R I N G S$

$\because-\sum 6-$ RINGS

\section{Mangrove core rings}

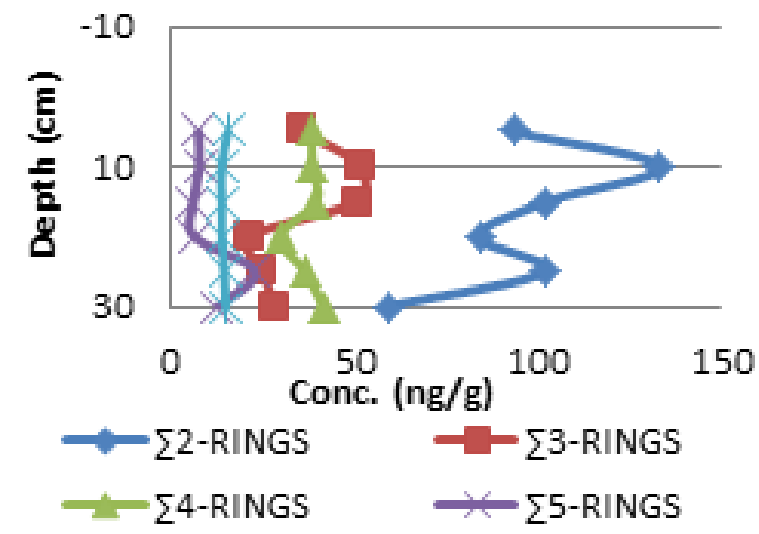




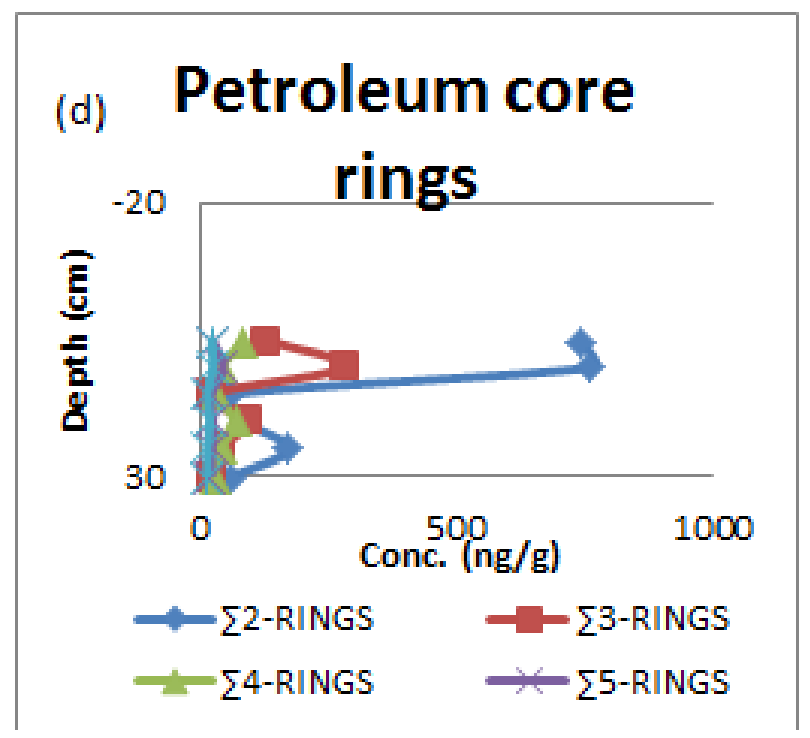

Fig. 2 a, b, c, d: Vertical distributions of PAHs by number of rings for (a) Afam, (b) Estuary,(c) Mangrove and (d) Illegal petroleum refinery cores

\begin{tabular}{|c|c|c|c|c|c|c|c|c|c|}
\hline DISTR $\#$ UTION PROFLE OF & CORES & IENT Q & $\begin{aligned} T \\
\text { VALTYY }\end{aligned}$ & $\begin{array}{l}\text { ABLEI } \\
\text { CHARAC }\end{array}$ & TERISTICS & Four $S$ & MPLDNG & 25 OF TH & ORVER \\
\hline & Sample & $\overline{\overline{\text { Depth }}}$ & $\begin{array}{l}\mathrm{TN} \\
\end{array}$ & TOC & TOCAN & & \begin{tabular}{c|} 
Grain siz \\
\end{tabular} & & \\
\hline Site & codes & $(\mathrm{cm})$ & (\%) & (\%) & $10 \mathrm{C} / \mathrm{N}$ & Sand(\%) & Silt(\%) & $\operatorname{Clay}(\%)$ & \\
\hline & $\mathrm{MSCl}$ & $25-30$ & 0.03 & 0.33 & 11.62 & 63.25 & 30.70 & 6.05 & \\
\hline & $\mathrm{MSC} 2$ & $20-25$ & 0.03 & 0.38 & 12.25 & 56.11 & 33.69 & 13.20 & \\
\hline Mangrove & MSC3 & $15-20$ & 0.029 & 0.35 & 12.06 & 49.88 & 41.02 & 9.10 & \\
\hline & MSC4 & $10-15$ & 0.035 & 0.35 & 10.01 & 53.26 & 23.41 & 23.33 & \\
\hline & MSC5 & $5-10$ & 0.029 & 0.42 & 14.02 & 71.06 & 20.14 & 8.80 & \\
\hline & MSC6 & 0.5 & 0.025 & 0.33 & 13.21 & 46.08 & 32.73 & 13.35 & \\
\hline & $\mathrm{ASCl}$ & $25-30$ & 0.049 & 0.96 & 19.09 & 57.66 & 20.16 & 22.18 & \\
\hline & $\mathrm{ASC2}$ & $20-25$ & 0.038 & 0.59 & 15.52 & 72.84 & 20.13 & 7.03 & \\
\hline Afam power & $\mathrm{ASC} 3$ & $15-20$ & 0.034 & 0.56 & 16.01 & 43.67 & 39.11 & 17.22 & \\
\hline station & $\mathrm{ASCA}$ & $10-15$ & 0.049 & 0.93 & 16.57 & 64.44 & 28.11 & 7.45 & \\
\hline & $\mathrm{ASC5}$ & $5-10$ & 0.050 & 1.02 & 19.98 & 46.23 & 27.17 & 26.6 & \\
\hline & ASC6 & 0.5 & 0.049 & 0.94 & 18.48 & 53.32 & 22.01 & 11.07 & \\
\hline & PSC1 & $25-30$ & 0.012 & 0.13 & 10.58 & 57.32 & 37.62 & 4.52 & \\
\hline & PSC2 & $20-25$ & 0.017 & 0.22 & 13.05 & 68.05 & 28.24 & 3.71 & \\
\hline Illegal Petroleum & PSC3 & $15-20$ & 0.008 & 0.1 & 12.51 & 53.07 & 22.01 & 11.32 & \\
\hline refinery & PSC4 & $10-15$ & 0.013 & 0.14 & 10.53 & 33.75 & 36.01 & 26.57 & \\
\hline & PSC5 & $5 \cdot 10$ & 0.007 & 0.14 & 18.49 & 73.31 & 22.64 & 4.05 & \\
\hline & PSC6 & 0.5 & 0.013 & 0.17 & 12.65 & 43.86 & 41.61 & 14.06 & \\
\hline & ESC1 & $25-30$ & 0.026 & 0.31 & 11.92 & 50.77 & 31.01 & 18.22 & \\
\hline & $\mathrm{ESC} 2$ & $20-25$ & 0.044 & 0.63 & 14.31 & 51.11 & 36.62 & 12.27 & \\
\hline Fatur. & ESC3 & $15-20$ & 0.049 & 0.94 & 19.18 & 48.78 & 32.06 & 19.16 & \\
\hline Estuary & ESC4 & $10-15$ & 0.047 & 0.72 & 15.31 & 66.23 & 22.06 & 11.68 & \\
\hline & ESC5 & $5-10$ & 0.049 & 0.86 & 17.55 & 63.01 & 28.38 & 8.61 & \\
\hline & ESC6 & 0.5 & 0.034 & 0.53 & 15.58 & $\begin{array}{l}47.71 \\
\end{array}$ & $\begin{array}{l}43.08 \\
43.08\end{array}$ & 9.21 & \\
\hline
\end{tabular}

The vertical distributions of TPAH for the Afam and Estuary cores are shown in Fig. 3a. In all depth intervals, the Afam core exhibited significantly higher TPAH concentrations than the Estuary core except at the middle layers $(15-20 \mathrm{~cm})$. Higher silt/clay fraction with relatively high TOC content $(0.94 \%)$ at the Estuary sediment layer (ESC3, 15-20 cm; Table 1) facilitated the adsorption and accumulation of PAHs, and may partly account for the relatively high level $(615.29 \mathrm{ng} / \mathrm{g} \mathrm{dw})$ found in this layer relative to ASC3 $(422.15 \mathrm{ng} / \mathrm{g} \mathrm{dw})$. The TPAH concentration measured at ASC5 (5 $10 \mathrm{~cm}$ ) was about 50 order of magnitude higher than those measured in other layers of the Afam core. According to field observation, there was a smell of oil in sample layer $(5-10 \mathrm{~cm}$; ASC5) from the Afam site but not in other layers, suggesting that oil contamination at the Afam site was not only localized but also accidental, and did not permeate significantly down core. An increase in TPAH from top layer $(0-5 \mathrm{~cm})$ to $15-20 \mathrm{~cm}$ depth interval and then decrease thereafter to the bottom layer $(25-30 \mathrm{~cm})$ was found for the Estuary sediment core. The differences in TPAHs between sediment layers for the Estuary core were not significant according to one way ANOVA test $(\mathrm{F}=3.56 ; \mathrm{p}=0.088)$, implying that depth did not have significant effect on the distribution of TPAH at this site.

Although the concentrations of naphthalene were pervasively high in all layers, higher proportion of high molecular weight (HMW) PAHs was apparent at the Estuary site relative to the Afam site (Fig.
4), supporting a higher proportion of pyrogenic inputs to the Estuary site.

Therefore, localization of the input sources played an important role in PAH contamination for the zones.

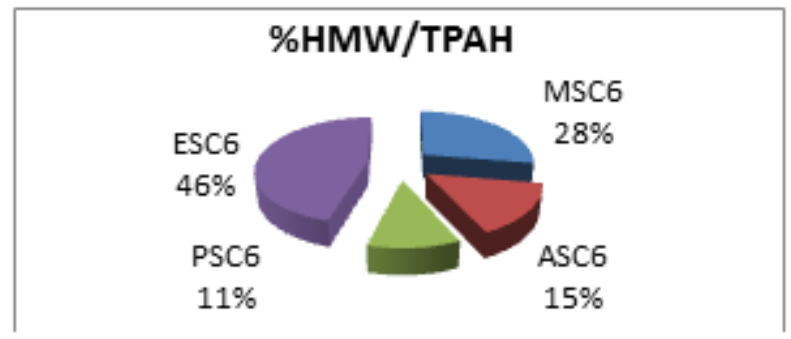

Fig. 4: Percentage of high molecular weight to total PAHs for surface sediments of the four sampling sites.

B. Spatial and Vertical Distribution of PAHs in Mangrove and Illegal Petroleum Refinery Sediment Cores.

Comparing surface sediment data between the Mangrove and illegal Petroleum refinery cores, the following distribution trends were observed for PAHs according to number of rings: $2->3->4->5-$ $>6$-rings and 2->3->5->4->6-rings, respectively (Fig. .2 c, d). The prevalence of 2- and 3- ring types is indicative of predominance of petrogenic over pyrogenic source input to the two zones, with higher proportion of fossil fuel combustion influence at the illegal Petroleum refinery site relative to the Mangrove site. There were no consistent trends in the vertical distributions of PAHs according to ring size for the two sites down cores. However, it appears that the 2and 3-ring types' levels remained highest at the same depth intervals $(5-10 \mathrm{~cm})$ for the two sediment cores (Fig., 2c and d), indicating that similar anthropogenic activity occurred during this time frame of sediment deposition.
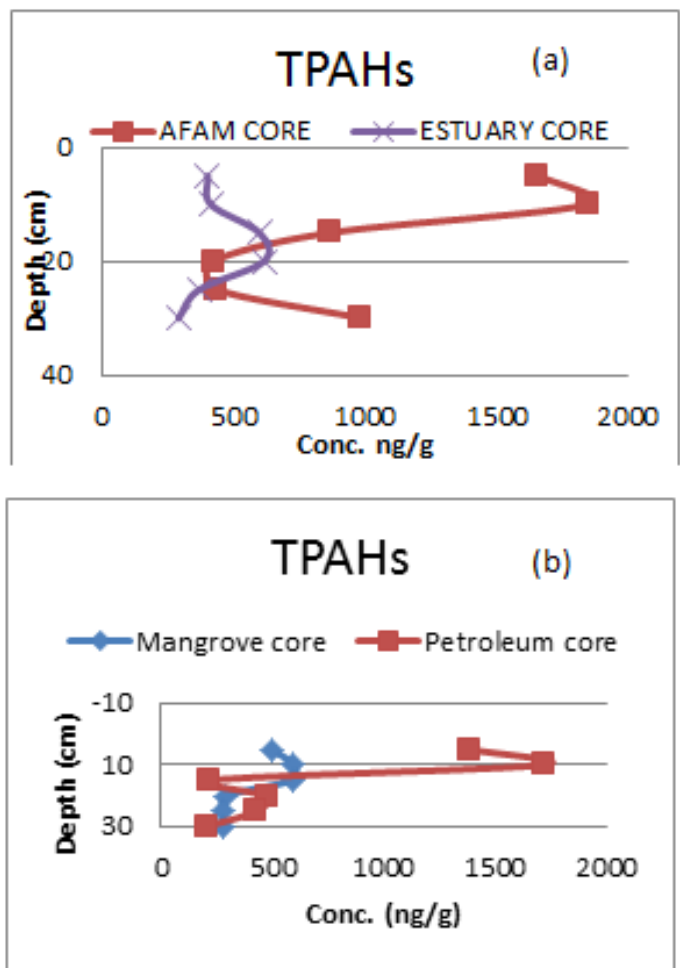

.Fig 3 a, b: Vertical distributions of TPAH in sediment cores from (a) Afam and Estuary zones, (b) Mangrove and illegal petroleum refinery zones

Note: ASC5 value was reduced by 50 order of magnitude in order to fit into the appropriate scale. 
The vertical distribution of TPAH in the Mangrove and illegal Petroleum refinery cores is shown in Fig $3 b$. In all layers, the illegal Petroleum core exhibited significantly higher TPAH concentrations than those in the Mangrove core except at MSC1 $(25-30 \mathrm{~cm})$ and MSC4 $(10-15 \mathrm{~cm})$ which exhibited a reverse trend. The distributions of TPAH down cores for the two zones did not follow any regular trend except that the TPAH levels peaked at near the surface layers $(5-10 \mathrm{~cm})$ and became minimized at the bottom layers $(25-30 \mathrm{~cm})$ for the two cores. Although, the entire cores are predominated by sand fraction, relatively higher silt/clay fractions and TOC contents were recorded for MSC5 $(5-10 \mathrm{~cm})$ and PSC5 $(5-10 \mathrm{~cm})$ layers, $(0.42 \%$ and $0.14 \%)$, respectively (Table 1$)$. These relatively high silt/clay fractions and TOC contents facilitated the adsorption and accumulation of PAHs in these layers and may to some extent account for the higher TPAH levels observed at this depth interval. In these two cores, sediment depth had no significant effect on the vertical distribution of the TPAHs (one way ANOVA test; $\mathrm{F}=3.4 ; \mathrm{p}$ $=0.09$ ). This value was less than the critical $F$ value of 4.96, implying that the levels of TPAHs in all layers did not vary widely over the time frame of sediment deposition.

The non-uniformity observed in the vertical distribution of percentage of HMW to TPAHs for the two sediment cores confirms that petroleum residue was not the exclusive source of PAH contamination (not shown) but that pyrogenic input arising from combustion of fossil fuel during the illegal local refining process was also evidenced. The result therefore confirms that localized contamination was not only evidenced between these two cores but also within each core.

\section{Historical Trends of PAHs Contamination}

It is a common knowledge that properties of sediment such as TOC would influence the distribution and concentrations of PAHs and other hydrophobic organic compounds [10]. In the present study, a good correlation existed between TOC contents and TPAH concentrations for the Estuary core with correlation coefficient value of $r^{2}=0.5663$. However, poor correlations were found for the illegal petroleum refinery $\left(r^{2}=0.0063\right)$, Afam $\left(r^{2}=0.2113\right)$ and Mangrove $\left(r^{2}=0.1069\right)$ core. This means that some local contamination sources might have interfered in the linear relationship between the PAHs and OC contents in the study area. Therefore, PAH concentrations were normalized by the respective OC contents to eliminate variations generated by the inherent property of the sediments such as OC.

Due to tidal influx and mixing arising from sediment resuspension, the estuary sediment might not have been well preserved. Thus, radiometric analysis for the Estuary core was not carried out. However, the estimated sedimentation rates for the other zones ranged from 0.32 to $0.58 \mathrm{~cm} /$ year with an average value of $0.47 \mathrm{~cm} /$ year. Accordingly, a $30 \mathrm{~cm}$ sampled core corresponding to about 5 decades time scale was used for this estimation.

The historical trends of normalized PAH distribution down cores are shown in Fig. 5 and indicates that the contamination was heaviest in the near top layers $(5-10 \mathrm{~cm})$ for the Afam, Mangrove and illegal Petroleum refinery cores, whereas the Estuary core was heavily impacted at the middle layer $(15-20 \mathrm{~cm}$; ESC 3$)$. The two heavily impacted layers (Mangrove, Afam and illegal Petroleum refinery cores; $5-10 \mathrm{~cm}$ ) and (Estuary; $15-20 \mathrm{~cm}$ ) according to this estimate correspond to the periods 1996-2004 and 1978-1986, respectively. This implies that $\mathrm{PAH}$ contamination of the river was very serious in the mid-1990s and 2000s, except at the Estuary zone. The prevalence of heavy impact in this period may be linked to frequent oil bunkering and/or oil pipeline vandalization activity by economic saboteurs. In June, 1998, a 16-inch underground Shell pipeline burst, discharging about 800,000 barrels of oil into the area [14]. Oil companies including Shell Petroleum Development Company operating in Nigeria often blame oil spills on armed militants operating in the Niger Delta, who campaign for a fairer allocation of oil revenue to locale in the oil-rich region. The contamination then dropped slightly to the most recent period $(0$ $5 \mathrm{~cm}$; except the significant drop attributable to the accidental discharge in the Afam core from 2004 to 2013). This decline is most likely due to the recent offer of amnesty and clamp down on vandals/militants by the joined armed forces empowered by the Nigerian government.

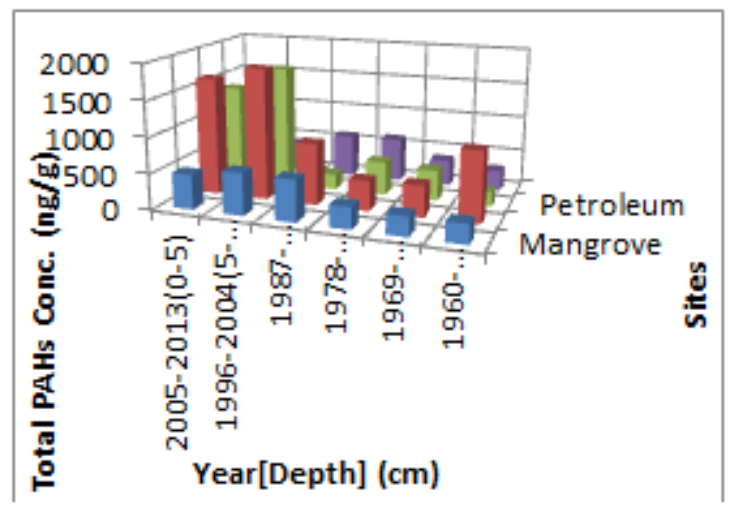

Fig 5: Vertical distribution of TPAH concentrations (ng/g) in the four Sediment cores of the Imo River showing historical contamination of PAHs.

Note: ASC5 value was reduced by 50 order of magnitude in order to fall into the appropriate scale.

Right from the first commercial discovery of petroleum in Nigeria in 1956, sediment cores from the Mangrove, Estuary and illegal Petroleum refinery zones except the Afam zone indicated gradual and steady increase up core in PAH contamination from early $1960 \mathrm{~s}(25-30 \mathrm{~cm})$ to mid-1990s $(5-10 \mathrm{~cm})$. These gradual increases may be associated with increasing urbanization with time. The slight decline observed thereafter signifies that despite the effort of the government to curb the activity of the saboteurs, some pockets of bunkering activity still persists going by the recent report accredited to the Minister of Petroleum.

In the case of the Afam core, the pattern varied slightly, showing a relatively high PAH contamination in the bottom layer $(25-30 \mathrm{~cm}$; 1960 -1968). The plausible explanation for this variation at the Afam core can be linked to the construction of the Afam power station complex (when input arising from utilization of natural gas and petroleum condensate for power generation was intensive) in the early 1960s. In addition, Eyama-Eleme, a village near the Afam area experienced an oil spill in the late 1960s caused by a fire explosion in which a vast area was buried under a hard-rock crust of burnt oil many feet thick [14]. This may likely contribute to the relatively heavy impact observed in this bottom layer.

On the other hand, at the Estuary sediment core, the heaviest PAH contamination that occurred at the middle layer $(15-20 \mathrm{~cm})$ appears to be linked to tidal influx of a major oil spill from offshore operation reported to take place in the early 1980s. Between 1976 and 1986, about 300 oil spill incidences were reported by oil companies operating offshore which spread over 2 million barrels of oil into coastal and offshore marine environment [14].

\section{Origins of Perylene in Sediment Cores}

This study was able to identify, in a single environment, for the first time, different sources of perylene by examination of its distribution patterns. Perylene has not only been reported by many researchers to be produced by insitu diagenesis of biogenic precursors of terrestrial organic carbon origin (e.g. [8, 5]) and aquatic origin (e.g. [ 8]), it has also been shown to be derived from anthropogenic sources [12].

In the present study, among the four surface sediment samples, perylene levels were more concentrated at the Estuary site which was 
within 5 orders of magnitude higher than those for other sites. This relatively high perylene level $(54.43 \mathrm{ng} / \mathrm{g} \mathrm{dw}$; found at the Estuary site where commercial fishery activity takes place may be associated with input of liquid fossil fuel combustion process arising from vehicular exhaust emission from boat traffic. This deduction is supported by the relatively higher proportion of percentage HMW to TPAH characteristic of pyrogenic source at the site. (Fig.4).

Furthermore, a comparison of vertical distribution profiles of perylene between Afam and relatively pristine Mangrove cores revealed different origins for the compound (Fig. 6). For instance, a uniform perylene distribution trend was found for the Mangrove site down core, indicating a constant production over the last 5 decades, most likely of diagenetic origin [4]. The Imo River sediment is dominated by terrestrial (land-derived) OC, and lesser amounts of aquatic (e.g. micro-algae) production evidenced by the TOC/TN ratios > 10 (Table 1); [13]. Therefore, the proposed biogenic production for perylene in the relatively pristine Mangrove core was rather linked to diagenesis of terrigenous OC instead of aquatic source.

On the other hand, in the case of a more contaminated Afam sediment core, an irregular perylene distribution pattern was found down core with an extremely high level ( $734.53 \mathrm{ng} / \mathrm{g} \mathrm{dw})$ recorded at 5 - $10 \mathrm{~cm}$ layer (ASC5; 1996 - 2004 when accidental discharge of crude oil occasioned by oil pipeline vanderlization was earlier reported to occur; Fig. 6). Since the Nigerian crude oil is believed to be predominantly derived from terrestrial OC based on the detection of oleanane, perylene occurrence at the Afam core can thus be traced to a non-marine petroleum source. Therefore, the Imo River environment represents one of the few environments suitable for the investigation of the diverse origins of perylene.

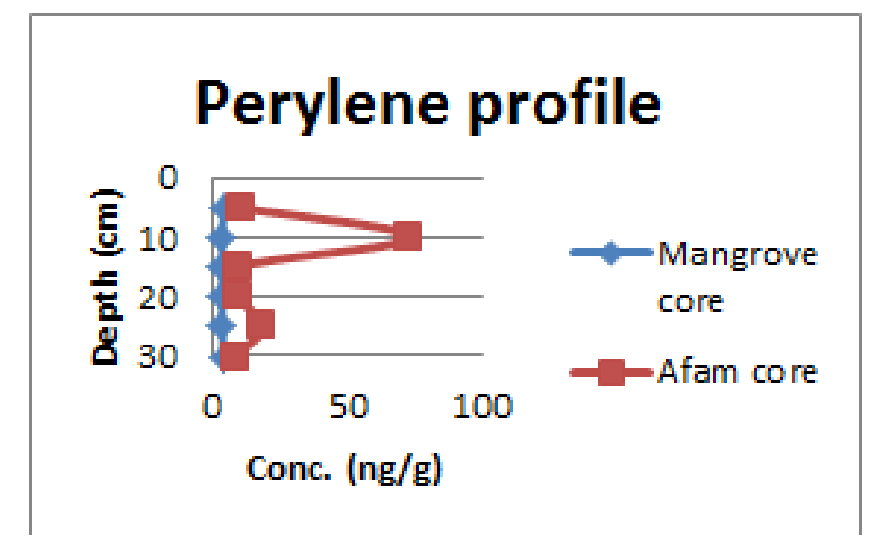

Fig. 6: Concentration-depth profile for Perylene in Mangrove and Afam Sediment Cores.

\section{CONCLUSIONS}

The Imo River environment provides a veritable means of tracing the diverse origins of perylene as well as assessing the historical trends of PAHs deposition since the first commercial discovery of crude oil in Nigeria in1956. The vertical distributions of perylene in the Mangrove site revealed a constant trend that suggests natural biogenic origin derived from terrigenous organic carbon. While pyrogenic origin of perylene was evidenced at the Estuary site supported by relatively high percentage of HMW to TPAH. A very high perylene level found at near the top sediment layer of the Afam core was linked to petroleum source as the deposition of this sediment interval coincided with the period when accidental discharge of crude oil occurred in the zone. Hence, in view of the uncertainty of the probable mechanism of perylene formation, we recommend that research effort be focused more on transformation pathways involving terrigenous rather than aquatic organic carbon. No regular trends were found in the distribution of TPAHs in all cores, except that this parameter peaked at near the top layers corresponding to the period of intensive bunkering and oil pipeline vandalization. A general decline were found in the TPAH levels from near top layers to the most recently deposited layers of the four cores, attributable to the recent offer of amnesty and subsequent effort of the Nigerian government in clamping down the illegal activity of economic saboteurs.

\section{REFERENCES}

[1] Appleby, P.G.,Richardson, N., Noland, P.J., (1992). Self-absorption corrections for well-type germanium detectors.Nuel.Inst.and Meth. 371, 228-233.

http://dx.doi.org/10.1016/0168-583X(92)95328-O

[2] Christensen, E. R. \& Arora, S. (2007). Source apportionment of PAHs in sediments using factor analysis by time records: application to Lake Michigan, USA.Water Research 23, $1-8$ http://dx.doi.org/10.1016/j.watres.2006.09.009

[3] Dominguez, C., Sarkar, S., Bhattacharya, M., Chatterjee, B., Bhattacharya, B., Jover, E., Albaiges, J., Bayona, J., Alam, Md. \&Satpathy, K. (2010).Quantification and source identification of polycyclic aromatic hydrocarbons in core sediemnts from sundarban mangrove wetland, India.Arch Environmental Contamination Toxicology 59, 49-61.

http://dx.doi.org/10.1007/s00244-009-9444-2

[4] Ekpo., B. O., Oyo-Ita., O. E., Oros, D.H.\& Simoneit, B. R. T. (2011). Distribution and sources of polycyclic aromatic hydrocarbons in surface sediments from Cross River estuary, S. E. Niger Delta, Nigeria.Environmental Monitoring and Assessment 34, 225-237

[5] Ekweozor, C.M. \&Telnaes, N. (1990).Oleanane parameter: verification by quantitative study of the biomarker occurrence in sediment of the Niger Delta.Organic Geochemistry 16 401-413. http://dx.doi.org/10.1016/0146-6380(90)90057-7

[6] Grice, K., Lu, H., Atahan, P., Asif, M., Hallmann, C., Greenwood, P., Maslen, E., Tulipani, S., Williford, K. \& Dodson, J. (2009).New insights to the origin of perylene in geological samples.Geochimica Et Cosmochimica Acta 73, 6531 -6543. http://dx.doi.org/10.1016/j.gca.2009.07.029

[7] Guo, J-y., Wu, F.C., Luo, X.J., Liang Z., Liao, H.Q. \&Zhang, R.Y.(2010). Anthropogenic input of polycyclic aromatic hydrocarbons into five lakes in western china. EnvironmentalPollution 158(6), 21752180 http://dx.doi.org/10.1016/j.envpol.2010.02.018

[8] Ke, L., Yu, H., Wong, S. \& Tam, Y. (2005). Spatial and vertical distribution of polyaromatic hydrocarbons in mangrove sediments. Science Of The Total Environment 340, 177-187. http://dx.doi.org/10.1016/j.scitotenv.2004.08.015

[9] Liu, Z., Zhang, H., Tao, M., Yang, S., Wang, L., Liu, Y., Ma, D. \& Zhiming, H., (2007). Organ chlorine pesticides in consumer fish and mollusk of Liaoning province ,China: distribution and human exposure implication. Arch. Environmental Contaminant \& Toxicology, 59, $444-$ 453. http://dx.doi.org/10.1007/s00244-010-9504-7

[10] Marynowski, L., Kurkiewicz, S., Rakocinski, M. \&Simoneit, B.R.T., (2011).Effects of weathering on organic matter: 1 . Changes inmolecular composition of extractable organic compounds by paleoweathering of a lower carboniferous (Tournaisian) marine black shale.Chemical Geology 285, 144 - 156. http://dx.doi.org/10.1016/j.orggeochem.2011.06.017

[11] Okpo, O. C \& Eze, R. C. (2012). Vandalization of oil pipeline in the Niger Delta region in Nigeria and poverty: an overview. Journal of Study in Sociology of Science 3(2), $13-21$.

[12] Oyo-Ita, O.E. \& Oyo-Ita, I.O. (2012).PAHs depositional history in recent core sediments from UkwaIbomlake, SE Nigeria.Environmental Geochemistry and Health 35, $189-199$.

[13] Oyo-ita, O.E. \& Oyo-Ita, I.O. (2013). Fatty acids and alcohols distributions and sources in surface sediments of the Imo River, SE. Niger Delta, Nigeria.Environment and Natural Resources Research 2, $101-113$.

[14] Oyo-Ita, O.E., Offem, J. O., Ekpo, B.O. and Adie, P. (2013).Anthropogenic PAHs in Mangrove sediments of the Calabar River, S.E. Niger Delta, Nigeria. Applied Geochemistry 28, 212 - 219. http://dx.doi.org/10.1016/j.apgeochem.2012.09.011

[15] Wilcke, W., Amelung, W., Krauss, M., Martins, C., Bandeir, R. A. \&Gracia, M. (2003).Polycyclic aromatic hydrocarbons (PAHs) patterns 
in climatically different ecological zones of Brazil.Organic

Geochemistry 34, $1405-1418$.

http://dx.doi.org/10.1016/S0146-6380(03)00137-2

[16] Zhang, R., Zhang, F.\& Zhang, T. (2013). Sedimentary records of PAHs

in a sediment core from tidal flat Haizhou Bay, China. Science of Total

Environment 450, 280-288.

http://dx.doi.org/10.1016/j.scitotenv.2013.02.029 